\title{
RADIOJORNALISMO ALTERNATIVO E DIVULGAÇÃO MULTIPLATAFORMA EM PROGRAMAS UNIVERSITÁRIOS
}

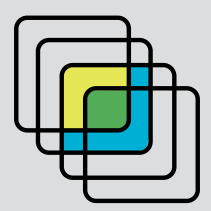

IV SICCAL

[ GT 2 - COMUNICAÇÃO, CULTURA E DIVERSIDADE ]

Luciano Victor Barros Maluly

Universidade de São Paulo

Carina Seles dos Santos

Universidade de São Paulo 


\section{[ RESUMO ABSTRACT RESUMEN ]}

Este artigo aborda a expansão do conteúdo multiplataforma do programa Universidade 93,7, que é produzido pelos alunos do curso de jornalismo da Universidade de São Paulo e veiculado pela Rádio USP FM. Além dos áudios, os estudantes fazem. gravações em vídeo, fotografia, matérias adicionais, entre outros produtos que são veiculados nas redes sociais. O objetivo é o de divulgar o programa e, assim, ampliar o número de ouvintes. Esta pesquisa demonstra a viabilidade ou não dessa estratégia de comunicação utilizada no programa Universidade 93,7, que é uma proposta alternativa de ensino de radiojornalismo, no ar há dez anos.

Palavras-chave: Ensino da comunicação. Multiplataforma. Radiojornalismo. Rádio USP 93,7 FM. Universidade 93,7.

This article approaches the expansion of the multiplatform content of the University 93.7 program, which is produced by the journalism course students of the University of São Paulo and broadcast by FM USP Radio. In addition to the audios, the students record videos, photography, additional matters, among other products that are broadcast on social networks. Aiming to disseminate through the program and, thus, broaden the numbers of listeners. This research aims the viability or not of this communication strategy used on University 93.7 program, which is an alternative proposal of teaching radio journalism, that's on for 10 years.

Keywords: Communication teaching. Multiplatform. Radio Journalism. 93.7 FM USP Radio. University 93.7.

Este artículo aborda la expansión del contenido multiplataforma del programa Universidade 93,7, que es producido por los alumnos de la carrera de periodismo de la Universidad de São Paulo y transmitido por la Radio USP FM. Además de los audios, los estudiantes hacen grabaciones en vídeo, fotografía, materias adicionales, entre otros productos que son difundidos en las redes sociales. El objetivo es el de divulgar el programa y, así, ampliar el número de oyentes. Esta investigación demuestra la viabilidad o no de esa estrategia de comunicación utilizada en el programa Universidade 93,7, que es una propuesta alternativa de enseñanza de periodismo radiofónico, en el aire hace diez años.

Palabras clave: Enseñanza de la comunicación. Multiplataforma. Periodismo radiofónico. Radio USP 93,7 FM. Universidade 93,7. 


\section{Introdução}

Em 2008, um grupo de alunos do curso de jornalismo - formado por Tadeu Breda, João Peres, Guilherme Balza e Tatiane Klein - solicitou ao então Chefe de Departamento de Jornalismo e Editoração da Escola de Comunicações e Artes da Universidade de São Paulo, José Luiz Proença, e aos professores das disciplinas voltadas ao radiojornalismo, Luiz Fernando Santoro e Luciano Victor Barros Maluly, que marcassem uma reunião junto à Superintendência de Comunicação Social (SCS) da USP. O objetivo era o de reivindicar um espaço na Rádio USP 93,7 FM para a transmissão dos programas produzidos por universitários.

A reunião aconteceu no SCS com o então coordenador, Wanderley Messias da Costa, o diretor da rádio na época, Celso dos Santos Filho, e a coordenadora de programação da emissora, Silvana Pires, os representantes do CJE, entre outros presentes. A conversa foi rápida e produtiva, com o SCS atendendo, imediatamente, a solicitação.

Naquele momento, nascia o programa Universidade 93,7, que é transmitido pela Rádio USP 93,7 FM, aos domingos, às 11 horas. O primeiro programa foi ao ar em 28 de setembro de 2008, devido às comemorações do Dia Nacional da Radiodifusão, data em homenagem ao Pai do Rádio no Brasil, Edgard Roquette-Pinto (1884-1954). O programa já estava gravado e teve a participação especial de Milton Parron, jornalista das rádios USP e Bandeirantes. O título era Palavras Cruzadas e teve a produção dos alunos André Albert, Ana Paula Bezerra
Severiano, Daniele Assalve, Henrique de Brito Garcia, Natália Favrin Ferri e Marcelo Augusto Spinel de Souza Cargano.

São mais de quinhentos programas produzidos nesse período de transmissões, sendo que o apoio operacional da emissora é fundamental ainda hoje, com destaque para as atuações de Dagoberto Alves e Aparecido Tavares, respectivamente, diretor e coordenador de programação da emissora. Da mesma forma, a dedicação dos funcionários do CJE, como Ulisses Rodrigues de Paula, idealizador do site do programa; dos técnicos Roberto Samarão Guimarães, Alexandre Munhoz Vieira, Carlos Alberto Martins Netto (já aposentados); Djalma Ferreira de Moraes, Alexandre Gennari de Aguiar e Willian Mathias de Oliveira tornou-se um diferencial para a produção do programa, justamente por facilitarem o trabalho dos alunos.

Os programas são gravados no velho Laboratório de Rádio João Walter Sampaio Smolka que, apesar das deficiências, ainda é um espaço de produção e convivência entre alunos, professores, funcionários e a comunidade externa.

A proposta didática alia o conhecimento dos conceitos em radiojornalismo e o compromisso para com os ouvintes. Assim, são produzidos radiojornais, especiais, entrevistas, entre outros formatos.

Dentro desse ideal, foram produzidos programas variados, desde o dia a dia do Hospital das Clínicas até a atual situação das escolas no Brasil. Da mesma forma, diversos artistas se apresentaram no programa, como o músico e professor da USP, Ivan Vilela, e o grupo cover da cantora norte-americana Janis Joplin. Temas complexos 
também foram debatidos, desde o aborto até os complexos testes em animais.

O Programa Universidade 93,7 também já foi objeto de pesquisas acadêmicas, como as dos professores Lourival Galvão Júnior (Universidade de Taubaté), em doutorado, e Daniela Cristiane Ota (Universidade Federal do Mato Grosso do Sul) e Janine Marques Passini Lucht, em Pós-doutorado.

O programa conquistou o Troféu São Paulo - Capital Mundial da Gastronomia, como melhor Reportagem Difundida em Emissora de Rádio em duas oportunidades. Em 2017, os alunos Alexandre Amaral, Bianca Kirklewski, Carolina Pulice, Felipe Fabrini, Helena Mega e Larissa Lopes venceram com o Especial Gastronomia em São Paulo. Já no ano seguinte, a equipe formada por Fernanda Giacomassi, Letícia Fuentes, Mariana Mallet Pires, Nara Siqueira, Vinícius Bernardes e Vinícius Sayão conquistou o prêmio com a cobertura sobre o Festival de Inverno com Jazze Fondue, que aconteceu no Bairro da Vila Madalena, em São Paulo.

A linha editorial aborda pautas do cotidiano voltadas ao interesse público e à cidadania, sempre com a intenção de defender os direitos humanos, especialmente a liberdade de expressão. Logo, o programa Universidade 93,7 da Rádio USP FM é uma conquista da Universidade de São Paulo, justamente por ser um espaço aberto, plural e democrático.

Nesses anos de transmissões, algumas alternativas em multiplataforma foram vislumbradas pelos alunos, monitores de graduação e pós-graduação e docentes, como um meio de expandir as formas de recepção e auxiliar na divulgação do programa. A plataforma digital foi um dos espaços encontrados para esse processo, principalmente pela facilidade no acesso e manuseio das chamadas mídias sociais e espaços compartilhados, principalmente o Facebook, o Instagram e o YouTube. Com o auxílio da equipe técnica do Departamento de Jornalismo e Editoração da ECA-USP, também foi possível construir um repositório (site) na internet para o acesso público às principais informações e arquivos. Nesses espaços, outras produções em audiovisual, como vídeos e fotografias, são postadas como um adendo à plataforma em áudio.

Até 2015, os programas contaram com a confecção de cartazes, iniciativa logo descartada devido ao custo da impressão. Uma outra alternativa foi a produção de adesivos, especialmente para carros, que é uma forma de divulgação um pouco mais duradoura e que se mantém em prática.

[ Figura 1]

Cartaz (2012)

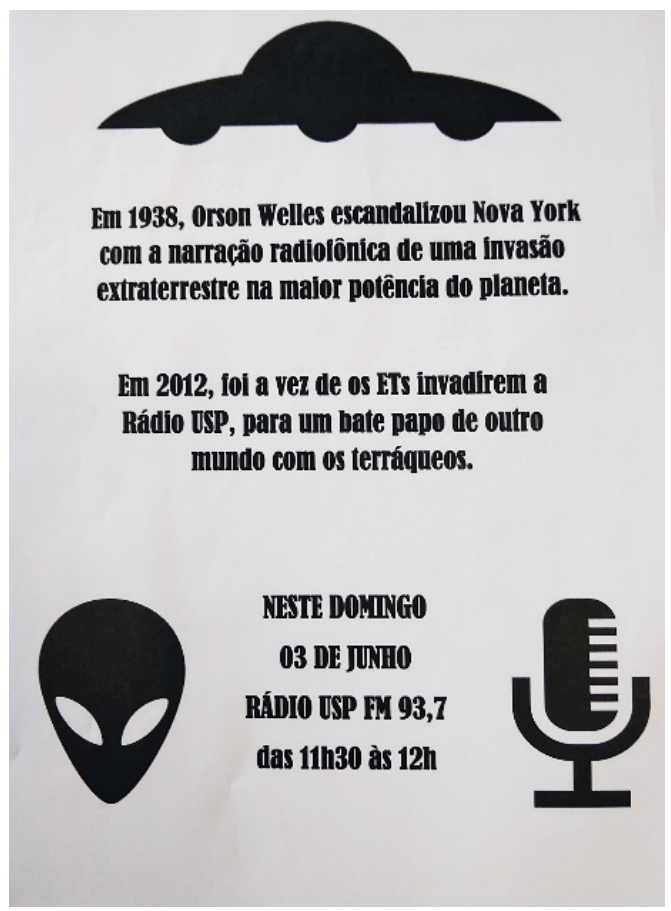


[ Figura 2 ]

Adesivo (2018)

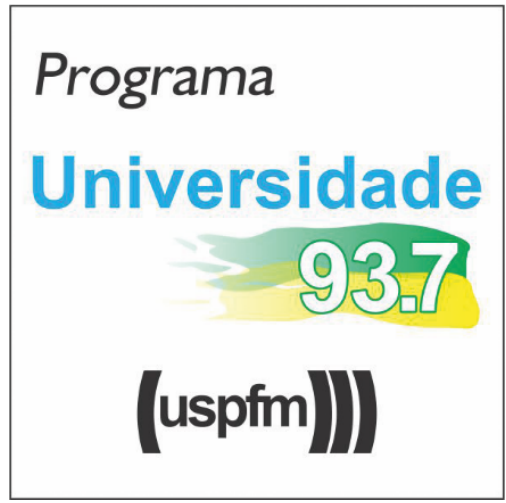

Este artigo tem, como objetivos, mostrar as técnicas utilizadas para disseminar o conteúdo produzido pelos alunos para diversos públicos e demonstrar se essas práticas são úteis para dinamizar/divulgar o trabalho da equipe (composta por discentes, docentes e monitores). Com isso, observa-se se esse trabalho facilita o acesso e a compreensão dos programas pelos ouvintes, ou é apenas mais problema que deve ser administrado por essa equipe. A referência metodológica para esta análise é a pesquisa-ação (THIOLLENT,1992, p.11), justamente pelos autores serem personagens desta análise, respectivamente, professor e monitora. Desta forma, este estudo pretende demonstrar as dificuldades e os acertos na implantação de multiplataforma nas disciplinas voltadas ao radiojornalismo do Curso de Jornalismo da Universidade de São Paulo, durante o segundo semestre de 2018.

\section{Conceitos sobre o rádio e multiplataforma}

A professora e pesquisadora da Universidade de São Paulo, Elizabeth Nicolau Saad Corrêa, ratifica o que se observa no dia a dia das pessoas quando analisa a aplicabilidade do universo digital. "As tecnologias digitais de informação e comunicação já estão plenamente consolidadas e a lógica das plataformas sociais de relacionamento em rede faz parte do cotidiano da sociedade" (SAAD CORREAA, 2016, p. 59). Essa afirmação é ainda comprovada quando se revela a expansão dos smartphones e, principalmente, a configuração do ciberespaço, como relata a professora e pesquisadora da Pontifícia Universidade Católica de São Paulo (PUC/SP), Pollyana Ferrari:

Por ter plasticidade e ser elástico, o ciberespaco nos permite misturar, articular e incorporar formatos não textuais em textuais, imagéticos em sonoros e vice-versa - tudo em um fluxo de negociações intersemióticas. (FERRARI, 2010, p. 79)

São essas tecnologias que conduzem ao pensamento do pesquisador em multiplataforma, no caso de Ramón Salaverría, professor de Jornalismo na Universidade de Navarra e diretor do Center for Internet Studies and Digital Life (CISDL), na Espanha. O autor destaca elementos que facilitaram a apresentação simultânea de vários tipos de elementos multimídia tornando versáteis os múltiplos formatos comunicativos. De acordo com Salaverría, os tipos de conteúdo multimídia possíveis até o momento na Internet são: texto, fotografia, gráficos, iconografia e ilustrações estáticas, vídeo, animação digital, discurso oral, música e efeitos sonoros e vibração (SALAVERRÍA, 2014, pp. 32-33). Dentro do conceito multimídia de Salaverría, está o contexto multiplataforma, ou seja, um conteúdo adaptado e coordenado em diferentes meios, de forma a "conseguir um melhor resultado conjunto" (SALAVERRÍA, 2014, p. 27). 
Neste aspecto, a multiplataforma está, por sua vez, inserida na cultura da convergência, como analisa o professor de Comunicação, Jornalismo, Artes Cinematográficas e Educação da Universidade do Sul da Califórnia, Henry Jenkins (2009). Para ele, o universo digital é o espaço "(...) onde as velhas e as novas mídias colidem, onde mídia corporativa e mídia alternativa se cruzam, onde o poder do produtor de mídia e o poder do consumidor interagem de maneiras imprevisíveis" (JENKINS, 2009, p. 29). O autor também aponta para uma outra possibilidade com a narrativa transmídia: "Uma história transmídia desenrola-se através de múltiplas plataformas de mídia, como cada novo texto contribuindo de maneira distinta e valiosa para o todo" (JENKINS, 2009, p. 138).

A pesquisadora e professora da Pontifícia Universidade Católica de São Paulo (PUC/SP), Martha Carrer Cruz Gabriel, analisa o conceito de Jenkins, trabalhado nas ações de comunicação no meio digital do programa universitário: "A convergência permite que a mesma mensagem/conteúdo seja consumida em diversas plataformas diferentes de mídia, tendo, portanto, como característica fundamental, a portabilidade" (GABRIEL, 2012, p. 175).

Este fluxo de conteúdo criado na web com forte destaque às redes sociais - faz com que os consumidores da plataforma (leitores, ouvintes, espectadores e outros) participem e interajam, sendo então, um processo cultural que estimula a participação dos consumidores de mídia, como observa a professora e pesquisadora da Universidade de Brasília (UnB), Nélia Rodrigues Del Bianco.

\begin{abstract}
A convergência de mídia é entendida aqui mais do que uma mudança tecnológica. É um processo cultural a considerar que o fluxo de conteúdo que perpassa múltiplos suportes e mercados midiáticos e os consumidores migram de um comportamento de espectadores passivos para uma cultura mais participativa. (...) Representa uma nova maneira de interagir com meios tradicionais, estabelecendo um outro patamar de cultura de relacionamento com o público. A convergência não é uma novidade no desenvolvimento dos meios de comunicação, sempre foi essencial no processo de transformação em todos os tempos, embora a observada na contemporaneidade tenha características diferenciadas por força dos recursos oferecidos pela tecnologia digital. (DEL BIANCO, 2012, p. 17)
\end{abstract}

Logo, torna-se próprio para esse artigo recuperar o conceito de rádio expandido proposto pelo professor e pesquisador da Universidade do Estado do Rio de Janeiro, Marcelo Kischinhevsky (2013), justamente para posicionar o leitor/ouvinte diante das possibilidades do radiojornalismo no contexto multiplataforma:

O rádio, expandido, transborda para as mídias sociais e serviços de microblogging, que potencializam a circulação de conteúdos jornalísticos nas redes sociais online. E, nesse contexto, crescem em importância as práticas interacionais mediadas por computador envolvendo áudio, como a etiquetagem (tagging) e compartilhamento de arquivos digitais, tanto por podcasters individuais quanto por grandes grupos de comunicação em busca de mais ouvintes para os conteúdos que veiculam em AM e FM (KISCHINHEVSKY, 2013, p. 7) 


\section{Estratégia de comunicação do programa Universidade 93,7}

\section{Site}

A primeira estratégia para multiplicação do conteúdo do programa Universidade 93,7 surgiu antes da estreia na Rádio USP 93,7 FM, quando da instalação do site de radiojornalismo, que está vinculado ao Portal da Universidade de São Paulo via Departamento de Jornalismo e Editoração da Escola de
Comunicações e Artes. O espaço foi viabilizado pelo funcionário Ulisses Rodrigues de Paula, com os alunos, monitores e docentes tendo acesso direto para a postagem dos arquivos em áudio, vídeos e fotografias, além das informações sobre o conteúdo (título, sinopse e dados da equipe, como locução, reportagem, produção e coordenação). O site antigo funcionou por mais de onze anos, de 18 de abril de 2006 até 16 de julho de 2017 . O site ainda está disponível para consulta dos arquivos antigos pelo link: http://www.usp. br/cje/radiojornalismo/antigo.

\section{[ Figura 3 ]}

Primeiro site do Programa Universidade 93,7

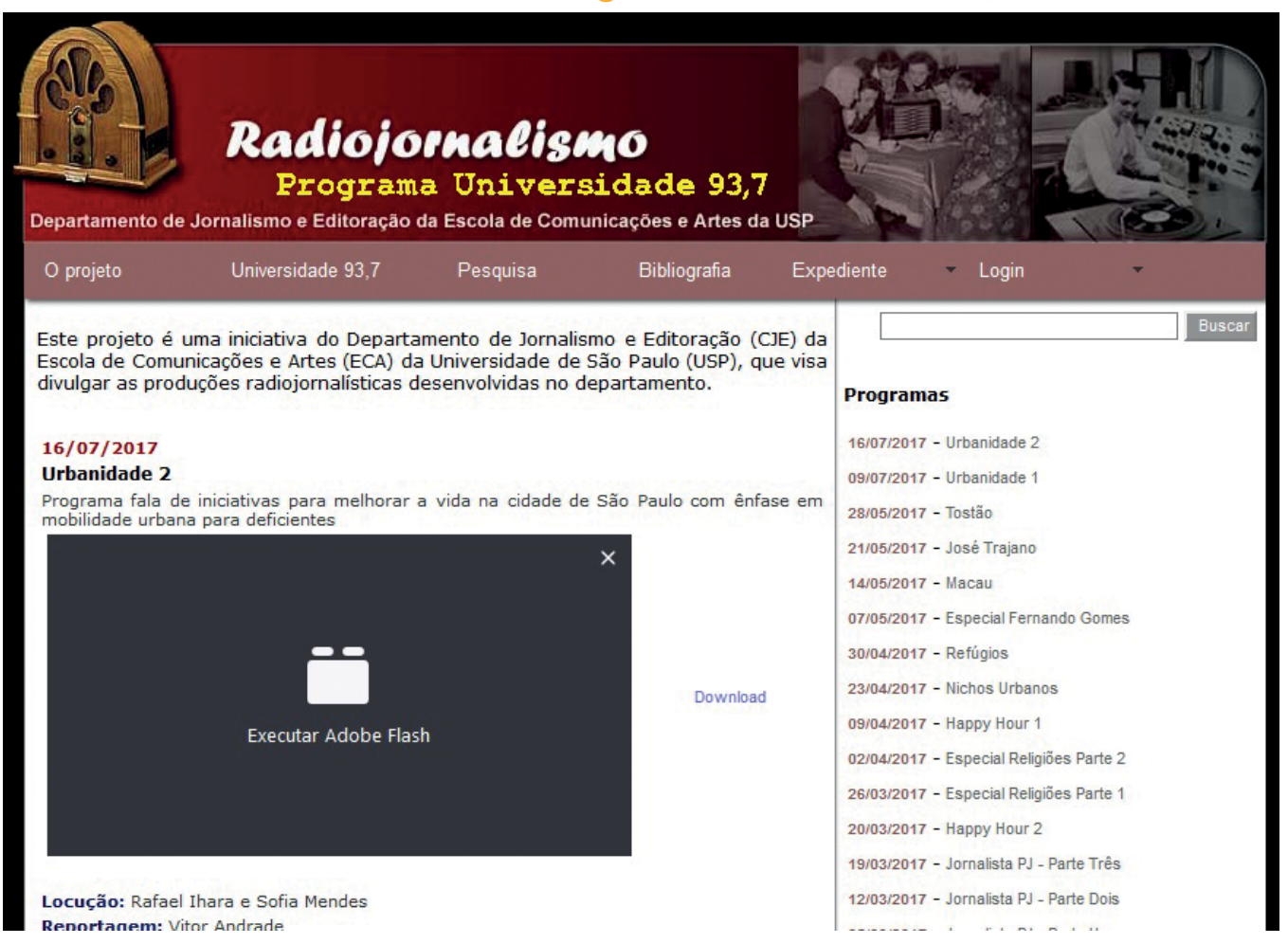

Fonte: Radiojornalismo-CJE-ECA-USP, $2006^{1}$

O novo site surgiu com o objetivo de facilitar a entrada dos programas via plataformas conhecidas, como YouTube, Mixcloud e Soundcloud, além da utilização

1 http://www.usp.br/cje/radiojornalismo/antigo/ index.php. Acesso em: 01.nov.2018. de uma tecnologia mais atualizada, visto que o site antigo executava os áudios somente em Adobe Flash Player. O site atual (http://usp.br/cje/radiojornalismo/) utiliza a plataforma Wordpress, com uma estrutura de fácil entendimento, atualização e navegação, ou seja, de fácil usabilidade 
nos dispositivos desktop (computadores e notebooks) e mobile (smartphones e tablets).

Com isso, além da postagem, o internauta também pode acessar o conteúdo por meio dessas plataformas. Apesar da entrada de áudio ser de fácil manuseio no Mixcloud e Soundcloud, o YouTube foi a plataforma de mais fácil adaptação pela equipe do programa. As informações disponibilizadas continuaram sendo as mesmas do site antigo.

\section{[ Figura 4]}

\section{Primeira postagem do primeiro site do Programa Universidade 93,7}

\section{8/04/2006}

\section{Palavras Cruzadas}

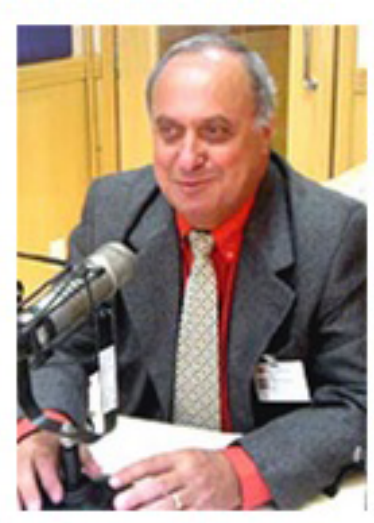

Este é o primeiro programa de rádio feito pelos alunos da Escola de Comunicações e Artes a ser disponibilizado na internet. Esta edição do programa Palavras Cruzadas conta as histórias de Milton Parron, jornalista que começou sua carreira na década de 50, primeiro na Rádio Avaré e depois na Jovem Pan (antiga Rádio Panamericana). Passou por todos os cargos na emissora e, em 1968, ganhou o Prêmio Esso. Ele fez a cobertura de casos notórios, como o seqüestro do menino Carlinhos, no Rio de Janeiro; o incêndio do edifício Joelma e os esquartejamentos cometidos por Chico Picadinho, em São Paulo. O programa Palavras Cruzadas é uma produção dos alunos do terceiro ano de jornalismo da Universidade de São Paulo.

Fonte: Radiojornalismo-CJE-ECA-USP, $2006 .^{2}$

\section{[Figura 5]}

Cabeçalho e primeira página do novo site do Programa Universidade 93,7 Últimos programas: Streaming de Video - Parte II $f$ 앙 붕
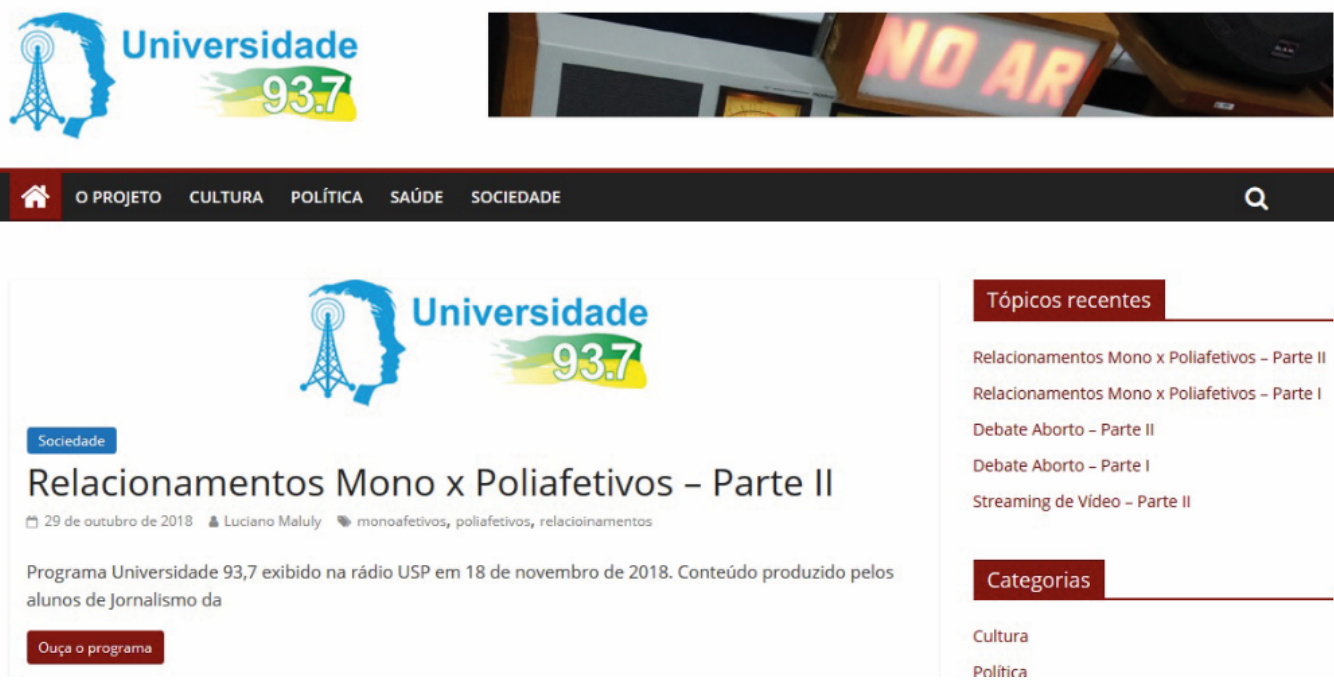

Fonte: Radiojornalismo-CJE-ECA-USP, $2018 .^{3}$

2 http://www.usp.br/cje/radiojornalismo/antigo/index.php?pageNum_exibir_programa=79\&totalRows_exibir_ programa=399. Acesso em 01.nov.2018.

3 http://www.usp.br/cje/radiojornalismo/antigo/index.php. Acesso em: 01.nov.2018. 


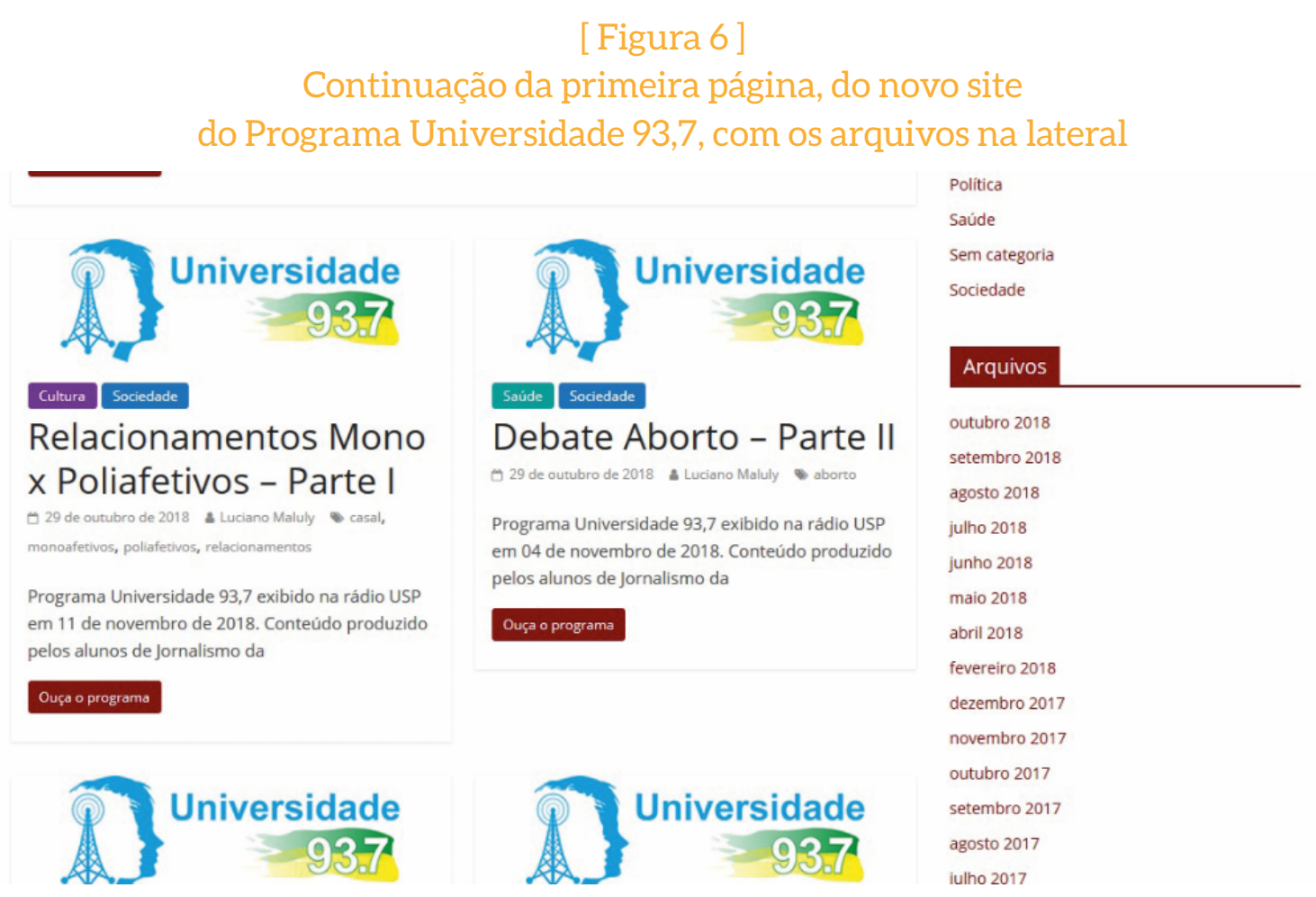

Fonte: Radiojornalismo-CJE-ECA-USP, $2018^{4}$

O início do processo de postagem no site era realizado pelo webdesigner do site (Ulisses Rodrigues de Paula), sendo transferido, posteriormente, para os docentes, depois alunos e, agora, é de responsabilidade dos monitores/estagiários da disciplina. Um manual foi elaborado pela aluna e monitora do PEEG (Programa de Estímulo ao Ensino da Graduação) da Disciplina CJE0532- Projetos em Rádio, Beatriz Quesada Barria Jorge, no primeiro semestre de 2018:

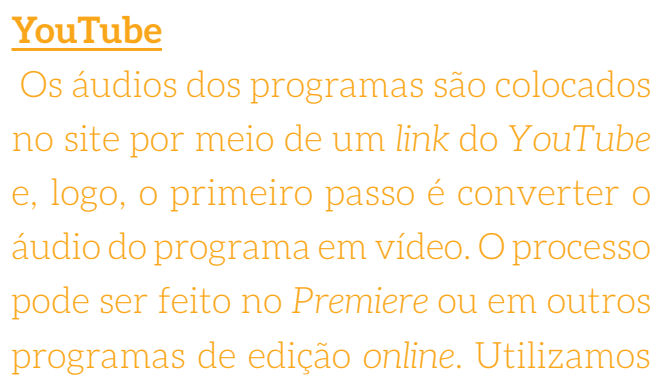

4 http://www.usp.br/cje/radiojornalismo/antigo/ index.php. Acesso em: 01.nov.2018. a foto padrão do logo do programa de fundo (foto em anexo).

Depois de convertido em vídeo, o programa deve ser postado no YouTube. Basta acessar a conta do Universidade 93,7 e fazer upload no site.

Na descrição do vídeo, especificamos que tipo de programa foi exibido, a data e os créditos dos alunos envolvidos. Exemplo: Programa Universidade 93,7, exibido pela Rádio USP no dia 08 de julho de 2018. Um especial sobre Novas Profissões produzido pelos alunos de Jornalismo da USP. Coordenação: Amanda Panteri Produção: Catarina Ferreira Pesquisa: Carla Garcia Edição: Regina Santana Locução: Isabella Galante Reportagens: Carolina Marins e Mel Pinheiro Também é possível catalogar os trabalhos por playlists que indicam os anos e semestres em que os programas foram produzidos. 
Conta de email: programauni937@gmail. com

Senha: XXXXXX

Site

O site é uma página em WordPress. Para adicionar um novo programa, deve-se clicar em "novo post", escolher um título, colocar na descrição os créditos e especificar a data e o tipo de programa a ser exibido. Para adicionar o vídeo, há um botão com o logo do YouTube - escolher a opção "embed a single video" e colar o URL do vídeo já postado no YouTube. Não esquecer de inserir uma categoria e definir uma imagem para ficar em destaque no site (ambas as opções ficam no canto direito da tela). As fotos destacadas podem ser o próprio logo do programa, imagens que tenham a ver com o tema ou fotografias dos bastidores das gravações.
Link: http://www.usp.br/cje/radio jornalismo/wp-login

Login: XXXXX

Senha: XXXXXX

(QUESADA, 2018)

Os vídeos começaram a ser produzidos como um produto adicional aos programas, sendo veiculados como chamadas e também para a veiculação de matérias extras. Um dos únicos e mais importantes vídeos foi produzido pelos alunos Bruno Capelas, Glenda Almeida, Leandro Carabet e Naíma Saleh durante a gravação do Especial Investimento Público e Olimpíadas, em outubro de 2012. O vídeo de quatro minutos e doze segundos contou com uma chamada para o programa em áudio e também com perguntas extras feita ao convidado, o Prof. Dr. Anderson Campos Gurgel.

\section{[ Figura 7]}

Material de vídeo "Olimpíadas no UNIVERSIDADE 93.7"

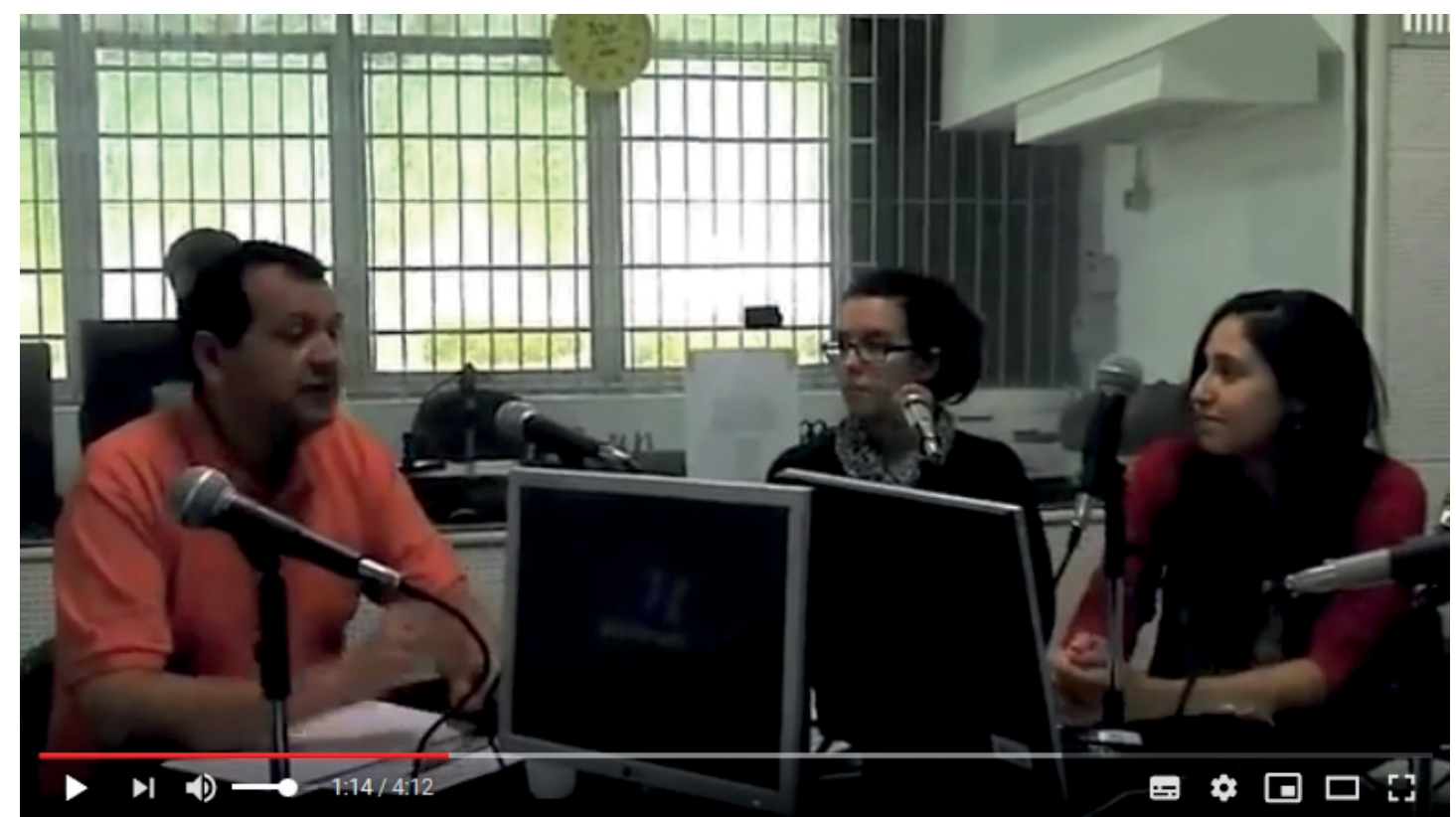

Fonte: RADIOJORNALISMO-CJE-ECA-USP, 2012. ${ }^{5}$

5 https://www.youtube.com/watch?v=jL9hl-dKz94. Acesso em 01.nov.2018. 
Atualmente, as chamadas em vídeo são gravadas pelos aparelhos móveis, como celulares smartphones. Porém, alguns programas, principalmente entrevistas, são gravados na íntegra em vídeo, mas ainda não estão disponibilizados no site de radiojornalismo do CJE. As gravações em aparelhos móveis são realizadas pelos alunos e monitores, sendo que as gravações com equipamentos profissionais em vídeo são realizadas com o auxílio dos técnicos, sendo também disponibilizadas no site do Departamento de Jornalismo e Editoração da ECA-USP (http://www.usp.br/cje/).
Alguns materiais em áudio produzidos pelos alunos, docentes e colaboradores também são disponibilizados no site de radiojornalismo. Geralmente, esses produtos são materiais adicionais aos programas ou mesmo gravações relacionadas à pesquisa, ensino, cultura e extensão. A série Tempo de Poesia, foi produzida pelo Prof. Dr. José De Paula Ramos Júnior, do Departamento de Jornalismo e Editoração da ECA-USP e transmitida, posteriormente, pela Rádio USP 93,7 FM, em 2015.

\section{[Figura 8 ]}

\section{Série Tempo de Poesia no site antigo do Programa Universidade 93,7}

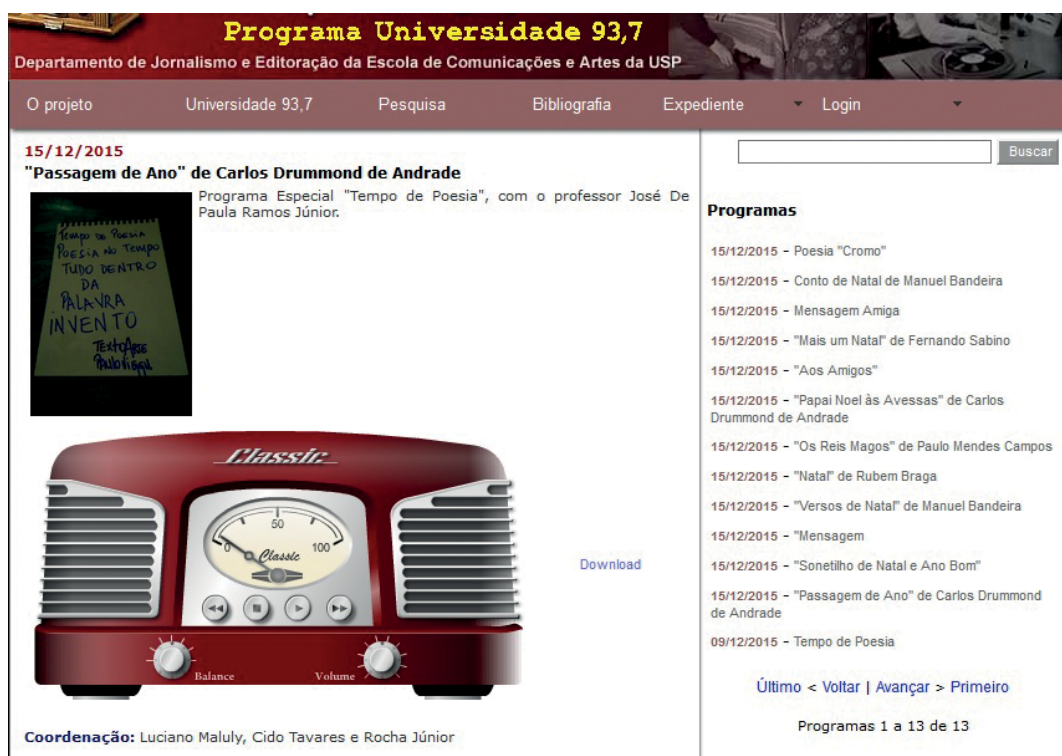

Fonte: Radiojornalismo-CJE-ECA-USP, $2015{ }^{6}$

\section{Facebook e Twitter}

Diante das redes sociais, as contas do Facebook (https://www.facebook.com/ programauniversidade937/) e Twitter (https://twitter.com/proguni937) foram

6 http://www.usp.br/cje/radiojornalismo/antigo/ index3.php?buscar=tempo+de+Poesia\&button=Buscar. Acesso em: 01. nov. 2018. criadas pelo aluno e também monitor da disciplina CJE0532 - Projetos em Rádio, Leonardo Barreiros Rocha, em 2010, com o objetivo de divulgar os programas e compartilhar conteúdos adicionais. As senhas foram disponibilizadas aos alunos, docentes e monitores para a postagem de fotos, links e informações sobre programas e eventos. A página do Facebook continua sendo utilizada pelos alunos, mas a conta no Twitter está inativa desde junho de 2017. 


\section{[ Figura 9]}

Página inicial do Facebook Programa Universidade 93,7

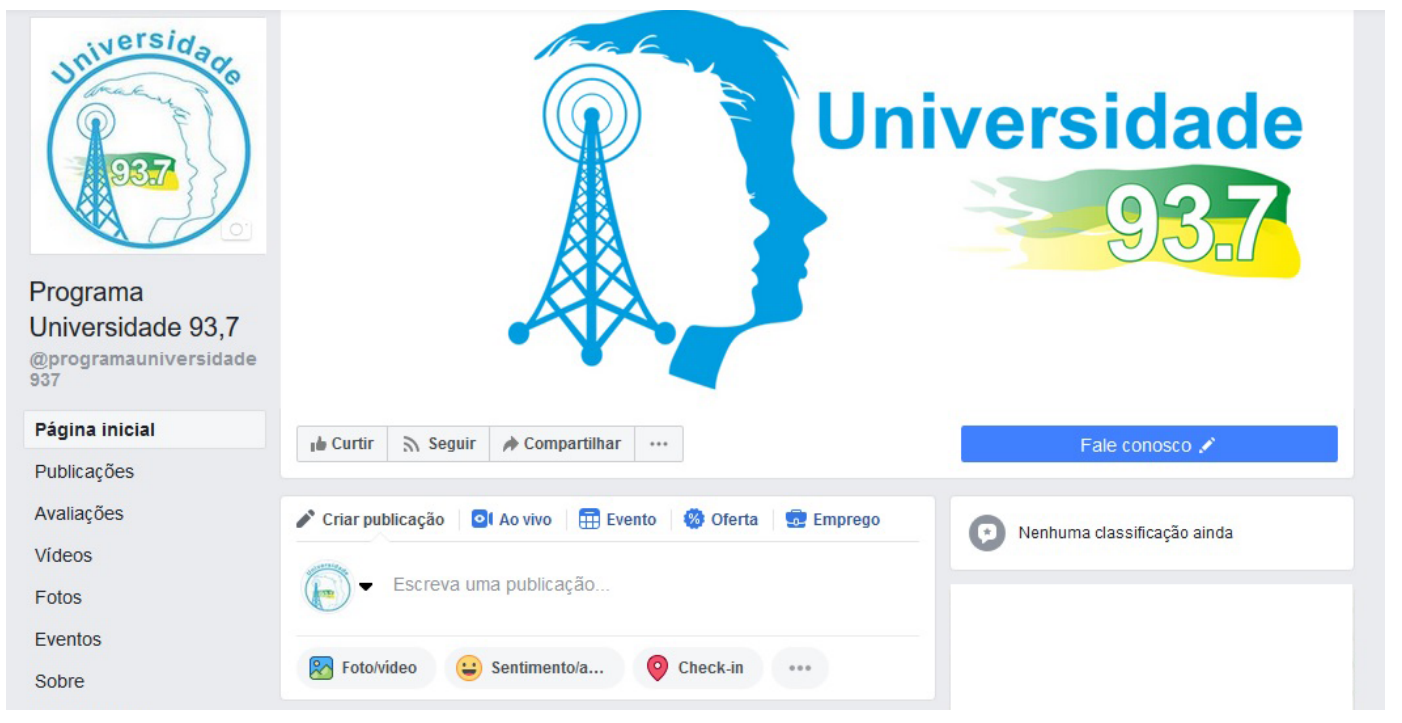

Fonte: Facebook, 2018.7

No Facebook, atualmente, os conteúdos publicados são links direcionados ao site novo do programa, que contém os áudios dos programas. O espaço também conta com fotos dos bastidores das gravações, como uma forma de mostrar o processo de produção dos programas radiojornalísticos e, também, para incentivar os alunos a compartilharem as postagens nas suas contas de Facebook pessoais para disseminar o conteúdo.

[Figura 10 ]

Modelo de postagem do Facebook Programa Universidade 93,7

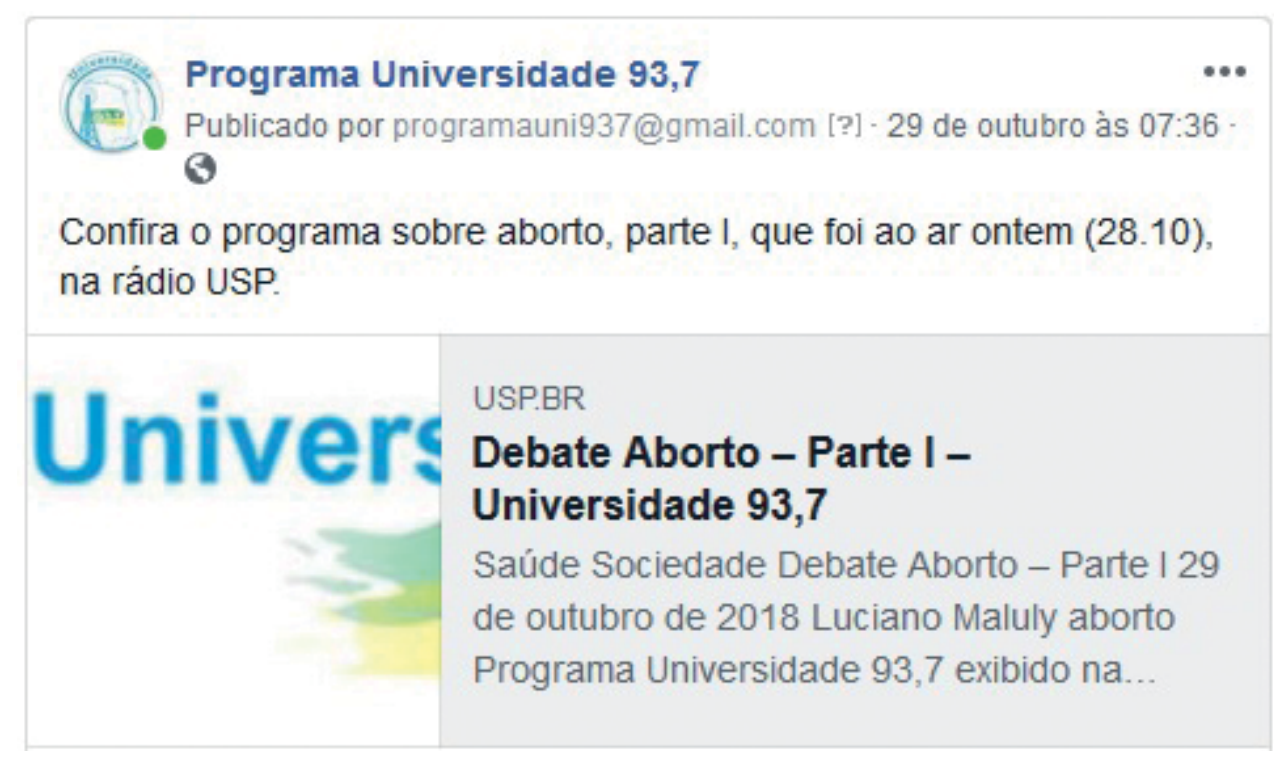

Fonte: Facebook, 2018. ${ }^{8}$

\footnotetext{
7 https://www.facebook.com/programauniversidade937/. Acesso em: 01. nov. 2018.
}

8 https://www.facebook.com/programauniversidade937/. Acesso em: 01. nov. 2018. 
A plataforma Facebook disponibiliza relatórios sobre o público que acessa a Fan Page do Programa para os administradores da conta na plataforma. Dados como idade, gênero, localidade e números de pessoas que visualizaram as postagens do Programa Universidade 93,7 em seus feeds de notícias são computados e enviados para os administradores da página na plataforma via e-mail e, também, disponíveis a qualquer hora nas configurações do Facebook do programa. Seguem abaixo, as últimas informações referentes aos resultados da plataforma:

[ Figura 11]

Público que curtiu a página no Facebook Programa Universidade 93,7

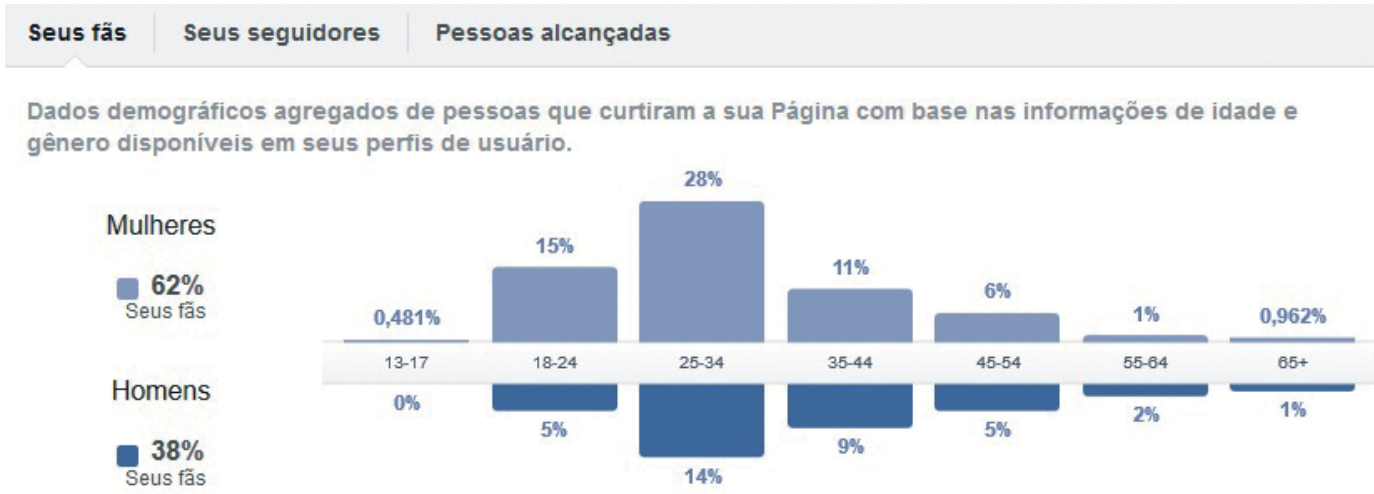

Fonte: Facebook, 2018.

[ Figura 12]

Público que curtiu a página no Facebook Programa Universidade 93,7

\begin{tabular}{|c|c|c|c|c|c|}
\hline Pais & Seus fãs & Cidade & Seus fãs & Idioma & Seus fãs \\
\hline Brasil & 200 & São Paulo, SP & 137 & Português (Brasil) & 189 \\
\hline Reino Unido & 2 & Guarulhos, SP & 4 & Inglês (EUA) & 10 \\
\hline Emirados Árabes Unid... & 1 & Osasco, SP & 4 & Inglês (Reino Unido) & 4 \\
\hline Canadá & 1 & Santos, SP & 3 & Espanhol & 2 \\
\hline Espanha & 1 & São Bernardo do Cam... & 3 & Português (Portugal) & 2 \\
\hline Grécia & 1 & Bragança Paulista, SP & 2 & Francês (França) & 1 \\
\hline Irlanda & 1 & Campinas, SP & 2 & & \\
\hline \multirow[t]{3}{*}{ Estados Unidos da A... } & 1 & Curitiba, PR & 2 & & \\
\hline & & Itapevi, SP & 2 & & \\
\hline & & Jundiai, SP & 2 & & \\
\hline
\end{tabular}

Fonte: Facebook, 2018. ${ }^{10}$

9 https://www.facebook.com/programauniversidade937/insights/?referrer=page_insights_tab_button. Acesso em: 01. nov. 2018.

10 https://www.facebook.com/programauniversidade937/insights/?section =navPeople>. Acesso em 01. nov. 2018. 
Com a análise dos dados, percebe-se que, dentre o total de 208 curtidas na página, mais da metade deste público são mulheres de 25 a 34 anos que moram na cidade de São Paulo. Neste caso, as interações ocorrem em maior quantidade quando há postagens sobre os arquivos em áudio, assim como fotos da produção e gravação dos programas. As postagens são esporádicas, ou seja, de acordo com as atividades práticas realizadas no estúdio.

\section{Instagram e E-mail}

As fotos sempre foram uma ferramenta acessível aos alunos, com sua divulgação sendo explorada, principalmente, após o uso do Instagram. A conta foi criada por Carina Seles dos Santos, aluna de mestrado do Programa de Pós-Graduação em Ciências da Comunicação e monitora PAE (Programa de Aperfeiçoamento de Ensino), da Disciplina CJE0532- Projetos em Rádio, no segundo semestre de 2018, como um meio para os alunos postarem as fotos e vídeos rápidos da produção dos programas.

O objetivo do uso da plataforma é estimular os alunos que estão presentes nesta plataforma, justamente para compartilhar as próprias produções dos programas de radiojornalismo. Um fato interessante é que, pelo uso contínuo de celulares e smartphones, a adaptação foi rápida. Os alunos começaram a postar as fotos automaticamente no aplicativo, nos mais diversos espaços oferecidos pelo Instagram, como ocorreu no dia 11 de outubro de 2018: publicações no feed de notícias (espaço principal de postagens de fotos e vídeos no formato quadrado que ficam permanentemente na conta do usuário), nos stories (postagens em formato vertical retangulares que ficam disponíveis por 24 horas) e nos destaques (postagens de stories que ficam salvas permanentemente em um espaço de destaque). Ainda não há vídeos no espaço IGTV do Instagram, ou seja, um espaço de vídeos na vertical que fica permanente na plataforma. ${ }^{11}$

\section{[ Figura 13]}

Postagens feitas pelos alunos e monitoria nos stories de 24 horas

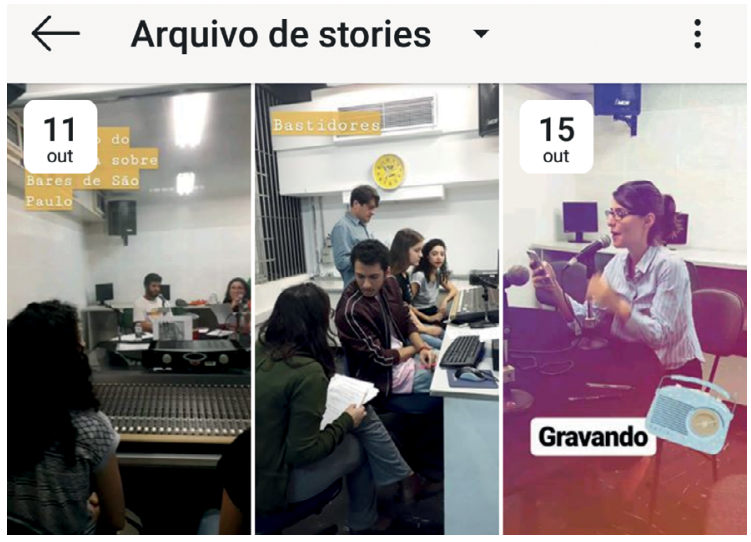

Fonte: Instagram, 2018. ${ }^{12}$

Por fim, observamos ainda a utilização e eficácia do e-mail do programa (programauni937@gmail.com),que ainda recebe as notificações dos ouvintes e da Rádio USP 93,7 FM, além de ser uma forma fácil de contato entre os envolvidos na produção do programa, bem como para o envio dos arquivos prontos à emissora.

11 Ver mais sobre os espaços de divulgação em:<https://instagram-press.com/>. Acesso em 01. nov. 2018.

12 No relatório da conta $<$ https://www.instagram.com/ programauniversidade937/>. Acesso em 01.nov.2018. 


\section{Considerações finais}

Apesar das multiplataformas existentes, a tentativa de ampliar a divulgação e o acesso ao conteúdo do programa Universidade 93,7 é mais uma iniciativa docente do que discente, ou seja, os professores e os monitores propõem e, muitas vezes, ficam encarregados da execução. Em poucas oportunidades, as propostas de produções ou compartilhamento surgiram dos estudantes. Fica, assim, uma dúvida diante do projeto pedagógico da disciplina ou mesmo dos cursos de jornalismo no Brasil, que deveriam propor matérias integradas em multiplataformas, reunindo os professores de rádio/áudio, vídeo/fotografia/TV, texto/impresso, designer/internet/online/ digital, e assim por diante. Desta forma, as pautas e produções se complementariam.

No caso deste artigo, os alunos ficam concentrados na construção dos áudios dos programas que são transmitidos todos os domingos, às 11 horas, na Rádio USP 93,7 FM. Com isso, os estudantes têm um retorno concreto, pois podem se ouvir através de uma emissora de rádio. Apesar da insistência na utilização das multiplataformas, existem poucas iniciativas por parte dos alunos em inserir conteúdos adicionais ou mesmo divulgar o programa em multiplataforma, especialmente as mídias sociais.

Todavia, esta estratégia tem potencial, pois estimula os alunos a conhecerem a integração das mídias e as possibilidades de convergência entre áudio, texto e vídeo. As próximas ações são pela continuidade da promoção do engajamento dos alunos nos programas de rádio integrado às redes sociais. Assim, é permitido produzir materiais extras das produções de rádio, como novas postagens no Instagram, YouTube e Facebook, estimulando os seguidores a ouvirem o programa ao vivo aos domingos, com postagens programadas nessas plataformas.

Muitas vezes, a gravação de conteúdos adicionais em audiovisual (fotos, textos, vídeo e áudio) ou mesmo a divulgação do programa torna-se um trabalho a mais para os alunos pois, afinal, a disciplina é de radiojornalismo e não de multiplataforma.

Neste caso, as plataformas digitais servem, de um lado, para ouvir os arquivos do programa pelo site (ou repositório) de radiojornalismo do Departamento de Jornalismo e Editoração da ECA-USP ou mesmo site da Rádio USP 93,7 FM, quando da transmissão ao vivo. Outro ponto é que esses espaços, principalmente as mídias sociais, auxiliam na construção da memória do programa, na interação com o público (quando algum contato), na manutenção dos arquivos, na atualização do cronograma das transmissões, entre outros aspectos.

A solução seria a interdisciplinaridade, ou seja, a construção de conteúdos integrados com as demais matérias de fotojornalismo, telejornalismo e jornalismo online e suas derivadas, com o objetivo de os alunos trabalharem esses conceitos simultaneamente. Contudo, esse trabalho precisa constar do projeto pedagógico do curso, além de contar com o apoio dos técnicos, auxiliares de ensino, monitores e estagiários. Não podemos esquecer ainda das condições físicas (e funcionais) dos laboratórios em multimídia, justamente para que a equipe consiga realizar essas tarefas com conforto. Sendo assim, a atualização dos equipamentos necessita ser periódica. 
Logo, o futuro já chegou e não será possível tapar os ouvidos para o avanço das tecnologias. Os cursos de jornalismo precisam se atualizar no sentido de promover disciplinas e atividades específicas voltadas à construção de webrádios e podcasting que sejam mantidos durante e fora do período letivo.
[ LUCIANO VICTOR BARROS MALULY ]

Possui graduação em Comunicação Social -

Habilitação em Jornalismo - pela Universidade

Estadual de Londrina (1995), Mestrado em

Comunicação Social pela Universidade Metodista de São Paulo (1998), Doutorado em Ciências da Comunicação (2002) e Livre-Docência (2016), ambos pela Universidade de São Paulo, além de Pós-Doutorado na Universidade do Minho, em Portugal (2011). Atua como professor e pesquisador na Universidade de São Paulo (USP), com experiência na área de Comunicação, com ênfase em radiojornalismo e jornalismo esportivo. E-mail: lumaluly@usp.br

\section{[ CARINA SELES DOS SANTOS ]}

É mestranda em Ciências da Comunicação pela Universidade de São Paulo (2018-2019), pós-graduada em Gestão em Comunicação Estratégica e Marketing (2014) e graduação em Comunicação Social Jornalismo pela Universidade Santa Cecília (2011). E-mail: carinaseles@usp.br. 


\section{Referências}

BIANCO, Nelia R. Del. Rádio e o cenário da convergência tecnológica. IN: BIANCO, Nelia R. Del. (org.) O Rádio Brasileiro na Era da Convergência. Grupo de Pesquisa Rádio e Mídia Sonora. São Paulo: Intercom, 2012. p. 16-37. Link: <portaldejornalismosul. espm.br/images/Stories/Ebook_Radio_na_era_da_Convergencia01_09_12.pdf >. Acesso em: 03.jul.2018.

FERRARI, Pollyana. (Org.). Hipertexto, Hipermídia: as novas ferramentas da comunicação digital. São Paulo: Contexto, 2010.

GABRIEL, Martha Carrer Cruz. Arte transmídia na era digital. Tese de Doutorado. Universidade de São Paulo, São Paulo, 2012. Acesso em: 27.jul.2018.

JENKINS, Henry. Cultura da Convergência. Trad. Susana Alexandria. São Paulo: Aleph, 2009.

KISCHINHEVSKY, Marcelo. Enunciação e etiquetagem de conteúdos da CBN - Análise da cobertura de uma tragédia carioca no rádio via internet. IN Revista Rádio-Leituras. Ano IV. Número II. Edição Julho-Dezembro 2013, pp. 06-24. Disponível em: https:// radioleituras.files.wordpress.com/2014/03/ano4num2.pdf. Acesso em: 06.nov.2018.

SAAD CORREAA, Elizabeth Nicolau. A comunicação na sociedade digitalizada: desafios para as organizações contemporâneas. IN: KUNSCH, Margarida M. K. Comunicação organizacional estratégica: Aportes conceituais e aplicados. São Paulo: Summus, 2016. p. 59-76.

SALAVERRÍA, Ramón. Multimedialidade: informar para cinco sentidos. IN: CANAVILHAS, João. Webjornalismo: 7 características que marcam a diferença. Covilhã: Livros LabCom, 2014. p. 25-51. Link: <https://www.researchgate.net/publication/268810050_ Multimedialidade_informar_para_cinco_sentidos>. Acesso em: 03.jul.2018.

THIOLLENT, Michel. Metodologia da pesquisa-ação. São Paulo: Cortez, 1992.

\section{LINKS:}

SITE PROGRAMA UNIVERSIDADE 93,7 ANTIGO. Disponível em: <http://www.usp.br/ cje/radiojornalismo/antigo/>. Acesso em: 01.nov.2018.

SITE PROGRAMA UNIVERSIDADE 93,7 ANTIGO. Série Tempo de Poesia. 2015. Disponível em: <http://www.usp.br/cje/radiojornalismo/antigo/index3. php?buscar=Tempo+de+Poesia\&button=Buscar>. Acesso em: 01.nov.2018. 
SITE PROGRAMA UNIVERSIDADE 93,7 NOVO. Disponível em: <http://usp.br/cje/ radiojornalismo/>. Acesso em: 01.nov.2018.

SITE CJE. DEPARTAMENTO DE JORNALISMO E EDITORAÇÃO. Disponível em: <http:// www.usp.br/cje/>. Acesso em: 01.nov.2018. 